\title{
Titus 3:3 As SELFVILIFIKASIE: 'N RETORIESE OPSIE
}

Author:

Aldred A. Genade ${ }^{1}$

\section{Affiliation:}

${ }^{1}$ Fakulteit Teologie, Skool vir Bybelwetenskappe en Antieke Tale, NoordwesUniversiteit, Potchefstroom Kampus, Suid-Afrika

\section{Correspondence to:} Aldred Genade

email:

aldredg@gmail.com

Postal address:

Fakulteit Teologie, Skool vir Bybelwetenskappe en Antieke Tale, NoordwesUniversiteit, Potchefstroom Kampus, Posbus 20004, Noordbrug, Suid-Afrika

\section{Keywords:}

Retoriek; Titus; vilifikasie; retoriese analise; evangelisasie; sending

\section{Dates:}

Received: 10 Nov. 2009

Accepted: 26 June 2010

Published: 05 Oct. 2010

How to cite this article: Genade, A.A., 2010, 'Titus 3:3 as selfvilifikasie: ' $n$ Retoriese opsie', Verbum et Ecclesia 31(1), Art. \#346, 5 pages. DOI: $10.4102 /$ ve.v31i1.346

\section{This article is available} at: http://www.ve.org.za
(C) 2010. The Authors. Licensee: OpenJournals Publishing. This work is licensed under the Creative Commons Attribution License.

\section{ABSTRACT}

Titus 3:3 as self-vilification: A rhetorical option The rhetorical function of the vice list in Titus 3:3 remains to be accounted for. This article proposes that self-vilification, a novel rhetorical technique, be considered to investigate and propose a rhetorical function for Titus 3:3. The result is the identification and formulation of the overarching rhetorical objective of the verse in its totality. Titus 3:3 expresses a valuable corrective to Christian attitudes that could compromise the evangelistic or missiological mandate of the Church today.

\section{INLEIDING}

Titus 3:3 bevat'n lys van sewe gedragspatrone of vergrype wat die vóór-Christelike toestand van onder andere die Kretaanse gelowiges beskryf (Fitzgerald 1992:857, 858). Akademici ignoreer grotendeels die funksie van die lys van gruwelhandelinge wat hierin voorkom en het dit nog nie by wyse van retoriese analise verreken nie. Besprekings van die vers word grotendeels beperk tot verduidelikings van die wyer konteks waarin dit voorkom. Verder oorskadu kwessies rakende struktuur en perikoopindeling die gesprek, terwyl die versinhoud merendeels slegs leksikaal aangeroer word. Wanneer retoriese analise van Titus 3:3 wel ter sprake kom, is dit meestal oorsigtelik en samevattend, sonder die naspeuring van enige retoriese funksie of doelstelling daarvan, en geen identifikasie van 'n (moontlike) nuwe retoriese tegniek vind hoegenaamd plaas nie. Daar blyk dus ruimte te wees vir ' $\mathrm{n}$ grondige retoriese bestudering van Titus 3:3. Die vers lees as volg:

Want ons was ook vroeër onverstandig, ongehoorsaam, op ' $n$ dwaalweg, verslaaf aan allerhande begeerlikhede en singenot; ons het in boosheid en afguns gelewe; ons was haatlik en het mekaar gehaat.

(1933-vertaling)

Titus 3:1-3 spreek tot Christene in die Suid-Afrikaanse konteks en samelewing. Hoe motiveer ' $n$ mens 'n gemeente of hoe maak ' $n$ mens hulle sensitief vir hul evangeliserende of missiologiese verantwoordelikheid in 'n samelewing waar soortgelyke gruwels soos dié in Titus 3:1-3 seëvier? Hoe reageer Christene in 'n konteks waarin die minagting van gesagstrukture (3:1) amper as 'n regverdigbare gedragskode uitgemaak word? Hoe kan ook Christene in Suid Afrika wakker geskud word tot die bewustheid dat die integriteit van die evangelie in gedrang kom wanneer 'n sondige samelewing Christelikheid met die antisosiale gesindhede van Christene vereenselwig?

Redes waarom die unieke aard van Titus 3:3 steeds weinig belangstelling wek, is uiteenlopend. Dat dit slegs 'n klein gedeelte van 'n groter perikoop en 'n nog groter hoofstuk beslaan, verklaar moontlik waarom die besondersheid daarvan nog nie onder die loep gekom het nie. Verder blyk die onbetwisbare verwantskap van 3:3 met enersyds 3:1-2 en met andersyds die daaropvolgende perikoop, 3:4-7, genoegsame verduideliking te bied vir die funksie daarvan as verklarend ten opsigte van 3:1-2. 'n Oorsig van die manier waarop Titus 3:3 oor die algemeen benader word, kan op grond van ' $n$ literatuurstudie aangetoon word. Dit word vervolgens onder die volgende opskrifte behandel:

- Algemene benaderings tot Titus 3:3

- Retoriese benaderings tot Titus 3:3

- Vilifikasie en selfvilifikasie

- Retoriese analise van Titus 3:3

- Slotopmerkings

\section{ALGEMENE BENADERINGS TOT TITUS 3:3}

Die inhoud van Titus 3:3 wek verskillende benaderings. Nuwe Testamentici behandel dit óf bloot kursories óf in meer detail. Volgens Bailey (1994:352) bevat Titus 3:3 slegs 'n beskrywing van diegene wat nog nie verlossing ontvang het nie. Miller (1997:136) konsentreer weer op die uiteenlopende literêre styl van 3:1-2 en 3:3-7 eerder as op die inhoud van vers 3. Hy beskou 3:3-8 as 'n interpolasie wat vreemd is in die onmiddellike konteks: dié gedeelte 'protrudes distinctly from the surrounding context' (vgl. Dibelius \& Conzelmann 1972:147).

Sommige navorsers benader die vers meer gedetailleerd. Knight (1992:335) voer aan dat die funksie van 3:3 tweërlei van aard is. Eerstens funksioneer dit redegewend ten opsigte van die voorafgaande paranese en is dit daarom verklarend. Tweedens dui dit in verhouding met die res van die hoofstuk vergelyking aan, naamlik die lewe vóór en ná verlossing (Knight 1992:336). Classen (2002:60) stem met hierdie interpretasie saam. Marshall $(2004: 305,306)$ is van mening dat 3:3-7 verklarend is, terwyl die $\sin$ in 3:3 die voor- en ná-verlossingstoestand van die lesers kontrasteer (vgl. Collins 2002:358; Dibelius \& Conzelmann 1972:147; Hultgren 1984:167).

Voorts is genoemde interpretasies gegrond op a priori-aannames rakende die toepaslikheid van hierdie gruweldade in Titus 3:3 op die geadresseerdes. Navorsers huiwer om die vergrype toe te pas op diegene wat hier as i $\eta \in \in \hat{i} s$, 'ons', geïdentifiseer word. Dus, so redeneer Quinn (1990:200), is hierdie lyste 'not biographical, much less autobiographical' en 'the items of this vice catalogue are not vices as such; they are adjectival of persons'. Sulke opmerkings verwater egter die betekenis wat die teks 
ten doel het, naamlik om oor die ontvangers te kommunikeer. Dit werp ook min lig op die funksie van die lys van vergrype.

Die struktuur van hierdie gedeelte lok veel belangstelling Kundiges identifiseer tereg die 'voorheen - nou' of 'тотє -ÖT $\epsilon$ '-skema wat hierdie perikoop kenmerk, en volstaan by die mening dat die doel van hierdie onderdeel is om die ou en nuwe mens te kontrasteer (Collins 2000:358). Towner (1994:253, 254) en Johnson (1996:245) beskou dit onderskeidelik as 'n oorgangsof bekeringsformule wat gebruik word om die oorskakeling na die nuwe lewe aan te dui. Volgens Mounce (2000:446) vorm Titus 3:3 deel van die teologiese motivering vir die soort gedrag wat in die voorafgaande perikoop gespesifiseer is. In hierdie opsig is die lys van vergrype nie soseer teen die opponente gefokus as wat dit die sonde van die mensdom oor die algemeen weerspieël nie. Towner (1994:253) redeneer dat die lys die realiteit van die verandering beklemtoon. Aanvullend hierby voer Hultgren (1984:168) aan dat verwysings na 'n vroeër lewe wat met die huidige een gekontrasteer word, 'n literêre meganisme is wat ten doel het om die voor-verlossingstoestand teologies te analiseer, en dat dit dus nie direk verband hou met die outeur of geadresseerdes van die brief nie. Fee (1988:202) is oortuig dat die lys die gevallenheid van die mens veralgemenend stel; hy sien in 3:3 'n evangeliserende motief vir die oproep in 3:1-2.

Terwyl al hierdie interpretasies hoogs waarskynlik en moontlik korrek is, ontbreek 'n bevredigende verduideliking vir die funksie van die lys steeds. Die skrywer kon byvoorbeeld op 'n ander manier of deur die gebruik van minder kras woordeskat die beskrywings verwoord het.

Hierdie oorsig, alhoewel kort en kursories, verteenwoordig die algemene benadering tot Titus 3:3. Dit word inleidend tot die perikoop (3:3-7) as redegewend en vergelykend in die breë konteks geïnterpreteer. Die lys van gruweldade word daarna leksikaal en/of etimologies verklaar. Die funksie van die lys van vergrype word selde buite hierdie algemene benadering verklaar en toegepas. 'n Mate van onwilligheid of onsekerheid kenmerk toepassing van die vergrype op 'n spesifieke gehoor.

\section{RETORIESE BENADERINGS TOT TITUS 3:3}

Alhoewel die moontlikheid dat Titus 3:3 'n retoriese funksie vervul, wel genoteer is, is dit nog nie indringend ondersoek nie. So 'n moontlikheid word wel erken of ten minste gesuggereer met verwysing na 'n keur uit die inhoud van die vers. Dus, volgens Johnson (1996:247) en Marshall (2004:306), is die voornaamwoord 'ons', $\dot{\eta} \mu \in \hat{\mathrm{i}} \mathrm{s}$, in Titus 3:3 retories gemotiveerd vir die daarstelling van 'n verhouding tussen die skrywer en ontvangers of om retoriese beïnvloeding tussen die partye te bewerkstellig (Du Toit 1992:282).

'n Paar navorsers waardeer oënskynlik die retoriese implikasies van die vers. Bernard (1980:177) se opskrif vir Titus 3 as 'We have no reason for pride' is 'n tree in die regte rigting. Dit openbaar'n aanvanklike waardering vir die retoriese implikasies van die vers. Ongelukkig brei hy nie hierop uit in die res van sy kommentaar nie. Simpson (1954:114) beskryf die doel van die lys as volg: 'to inspire disgust'. Hierdeur erken hy 'n retoriese funksie van die lys. Quinn (1990:208) moet gelyk gegee word wanneer hy uiteindelik die funksie van die lyste erken en beskryf as 'bring[ing] the reader up short'. Die huidige stand van navorsing is van so 'n aard dat navorsers nie op hulle bevindinge uitbrei nie, met die gevolg dat die ondersoek na retoriese funksie grotendeels gekortwiek of geïgnoreer word.

Die meerderheid skrywers toon egter min waardering vir die 'affektiewe' funksie van die lyste, veral die lys van vergrype. Dat so 'n funksie bestaan, is duidelik uit die opmerkings van bogenoemde navorsers. Verder is dit die aard van Bybelse literatuur dat dit wil oortuig - 'n faktor wat in huidige literatuurstudies grotendeels oor die hoof gesien word. 'n
Skrywer wat poog om te oortuig, moet uiteraard die teikengehoor deur middel van die geskrif 'beweeg' en dus affekteer. In hierdie verband lewer Du Toit (1994) 'n waardevolle bydrae:

We have too long neglected the fact that in one way or another each of these writings seeks to persuade its readers/audience in a certain direction. To ask what a New Testament text is doing is at least as important as asking what it is saying

(Du Toit 1994:403)

Bydraend hierby noem hy elders dat:

in persuasive texts the real (empirical) author sets out to manipulate his real readers towards a specific objective by means of encoding himself and his readers in such a way and applying such textual strategies as will expedite the desired effect

(Du Toit 1989:192; beklemtoning bygevoeg)

Dit is die uitgangspunt van hierdie skrywer dat die lyste inderdaad bedoel was om die ontvangers te affekteer. Die grafiese beskrywing van die gruwels verwek selfs in 'n moderne gehoor of leser afsku en skaamte. Johannes Calvyn het in sy kommentaar (Calvin 1856:325-326) vroeg reeds die retoriese impak van die vers gesnap. Ter illustrasie word die volgende uit sy kommentaar op die Pastorale briewe aangehaal:

Nothing is better adapted to subdue our pride, and at the same time to moderate our severity, than when it is shewn that everything that we turn against others may fall back on our own head ... In order that believers, therefore, may not haughtily and cruelly mock at others, who are still held in their ignorance and blindness, Paul brings back to their remembrance what sort of persons they formerly were; as if he had said, 'if such fierce treatment is done to those on whom God has not yet bestowed the light of the gospel, with equally good reason might you have been at one time harshly treated. Undoubtedly you would not have wished that any person should be so cruel to you; exercise now, therefore, the same moderation towards others

(Calvin 1856:325-325; beklemtoning bygevoeg)

Dít is ongelukkig die einde van die bekroonde Geneefse eksegeet se insae tot die retoriek van die vers. Die leemte bestaan dus nog vir 'n grondige analise en beskrywing van die retoriese funksie van Titus 3:3.

Is 'n klagte dat die retoriese rol van Titus 3:3 doelbewus nie waardeer word nie, heeltemal regverdigbaar? Nee. Regverdige akademiese oordeel vereis 'n toegewing. Dit is op stuk van sake net één vers in 'n baie groter konteks. Tog word in Titus 3:3 n baie belangrike retoriese doelstelling ontbloot deur middel van 'n ewe belangrike retoriese tegniek wat nog nie in die Titus-brief (of elders) geïdentifiseer is nie. Vervolgens stel hierdie outer ' $n$ nuwe konsep voor, naamlik selfuilifikasie, as beskrywend van die retoriese tegniek wat in Titus 3:3 funksioneer. Die konsepte 'vilifikasie' en 'selfvilifikasie' moet nou aandag geniet.

\section{VILIKASIE EN SELFVILIFIKASIE}

Die tegniek selfvilifikasie is 'n gepaste beskrywing van Paulus se retoriese oogmerk met die lys in Titus 3:3. Vervolgens word hier geoordeel dat selfvilifikasie, soos vilifikasie, as 'n retoriese tegniek erken moet word, omdat die twee konsepte in werklikheid identies in Titus funksioneer. Ten einde die funksie van selfvilifikasie te verstaan, word derhalwe 'n oorsig van die meer bekende konsep vilifikasie gegee.

\section{Vilifikasie}

Vilifikasie is 'n retoriese tegniek wat universeel in mondelinge en skriftelike kommunikasie gebruik word (Du Toit 1992:285). In die Hellenistiese tydperk is dit algemeen deur filosowe, redenaars en sofiste gebruik, met inbegrip van Christen- en Joodse filosowe (Du Toit 1994:404; Forbes 1986:3-15; Johnson 1989:430-434). 'n Skrywer of spreker het dit gebruik om 'n opponent in onguns te bring deur dié te verneder of te bespot (Botha 1993:421). Die oogmerk was om hoorders/lesers te oortuig om hulle van die teenstander(s) te distansieer of te 
vervreem (Du Toit 1992:285) en om die standpunt of persoon van die spreker/skrywer te ondersteun en hulle daarmee te laat identifiseer.

'n Tendens wat die toepassing van die tegniek illustreer, is om die opponent van morele integriteit te ontsê (Du Toit 1994:409). In sy uitstekende artikel noem Johnson (1989:432) dat die standaardisering van sekere lasterfrases gou deel van die vilifikasie-tegniek geword het. Sy artikel bevat talle voorbeelde van beswadderingsfrases. Die diskoerse van Dio Chrysostomos (Chrysostom 1949) van Prusa illustreer die gebruik van sodanige beswaddering van opponente. Vroeër 'n sofis, maar bekeer tot die filosofie, vaar hy uit teen die sofiste in taal sowel as toon wat verbasend aan dié van Titus en spesifiek Titus 3:3 herinner. Hy beskryf die sophistai onder andere as:

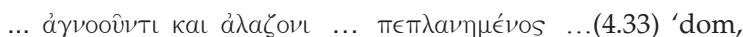
verwaand, selfbedrieg'

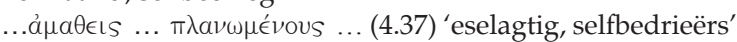

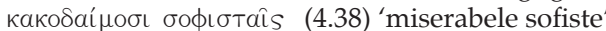
a

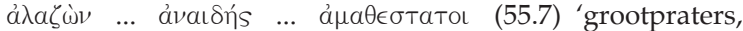
skaamteloos, onnosel'

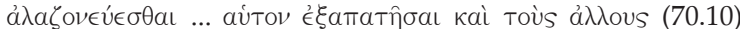

'diegene wat hulself sowel as ander bedrieg'

Die primêre oogmerk met die gebruik van vilifikasie is om die gehoor/lesers te oorreed om hulle van die opponent te distansieer. In hierdie proses van oorreding word in baie spesifieke woordeskat gebruik. Gestandaardiseerde uitdrukkings word ook gebruik, soos die voorbeeld hierbo illustreer.

In die lig van bostaande oorsig kan nou na die betekenis van selfvilifikasie gekyk word.

\section{Selfvilifikasie}

In Titus 3:3 is die gemeente die teiken van die vilifikasie, spesifiek die gruweldade wat vroeër hul etiek gekenmerk het. Deur hierdie retoriese tegniek wil die skrywer die gemeente oorreed om hulle te vervreem van die kwaadaardige gedrag waaraan hulle hul vroeër skuldig gemaak het. Hulle moet die gedrag wat in Titus 3:1-2 vereis word as deel van hul nuwe identiteit beoefen.

Selfvilifikasie is dus in baie opsigte identies aan vilifikasie, maar dít wat afgekeur word of waarvan vervreem moet word, is intern of subjektief - in hierdie geval die negatiewe gedragspatrone van die gemeente. Dít waarmee geassosieer of identifiseer word, is die positiewe gedragspatrone, soos deur Paulus voorgeskryf en aanbeveel.

Vervolgens word 'n retoriese analise van Titus 3:3 gedoen om in die lig van die tegniek van selfvilifikasie die oorkoepelende retoriese motief vir die vers te bepaal.

\section{'N RETORIESE ANALISE VAN TITUS 3:3}

In hierdie artikel word uitsluitlik op die retoriese aspekte van Titus 3:3 gekonsentreer. Goeie woordstudies van die versinhoud is beskikbaar in die talle kommentare wat die Pastorale briewe behandel vir diegene wat in die woordeskat van die vers belangstel.

Die metodologiese benadering wat in hierdie verhandeling gevolg word, is die 'minimale teoretiese raamwerk' van Tolmie (2005:28-29). Met die teks as beginpunt, behels dit dat die

1.Alhoewel outeurskap nie die uitgangspunte wat hier gehuldig word, beïnvloed nie, onderskryf die outeur van hierdie artikel die Pauliniese outeurskap van die Pastorale briewe. Sodanige voorveronderstelling geniet wye ondersteuning ten spyte van die heersende akademiese tendens wat nie Pauliniese outeursap aanvaar nie. die hecrsende akadeniese Dus, aangesien die identiteit van die outeur van die Titus-brief nie' $h$ invloed op die argument van hierdie artikel het nie, word volstaan met 'Paulus', soos die outeur oorkoepelende retoriese oogmerk bepaal en beskryf word en dat retoriese tegnieke en argumente geïdentifiseer word.

Die sewe positiewe oproepe in Titus 3:1-2 vind in 3:3 $\mathrm{n}$ teenwig met die vermelding van sewe vergrype. Daar is duidelik 'n poging om die luisteraars/lesers met afsku te vervul; om hul tekortkomings bloot te lê. Die vraag is, waarom? Hoe kan die uitgesprokenheid van die apostel, die grafiese uitwys van gruwelhandelinge, geregverdig word? Wat is die funksie van hierdie selfvilifikasie? Die antwoord lê in die onmiddellike en wyer konteks, spesifiek die oproep tot die beoefening van gesonde leer, ugia inoush/didaskalia/(vgl. 1:9, 2:1). Die lys in die vorige perikoop (vgl. 2:2-10) is 'n positiewe beskrywing van daardie soort dade wat met gehoorsaamheid aan gesonde leer vereenselwig word.

Die semantiese verhoudings en retoriese doelstellings is bevorderlik vir die samehang en die kontekstuele verwantskap van die vers. Daar is reeds na die funksie van die enklitiese partikels (of: sogenaamde p ot e-roł e formule) verwys (vlg. bl. 5).

Die retoriese gebruik van die werkwoord hmen en diepersoonlike voornaamwoord hmei " wat hier as 'identiteitsmerker' funksioneer, vereis kommentaar. Die doel is duidelik die beklemtoning van inklusiwiteit en om identifikasie tussen die onderskeie drie partye, naamlik die apostel, Titus en die Kretaanse gelowiges, in die hand te werk (Du Toit 1992:282-83; Mounce 2000:446).

Quinn(1990:201) beweer dat diegebruikvandievoornaamwoord 'n verhoudingsfokus aandui. Mounce (2000:446) voer aan dat dit 'n beklemtonende funksie het - om daardeur die kontras tussen die lewe in die nie-Christelike verlede en Christelike hede te verskerp. Hoe dit ook al sy, die primêre doel is seer sekerlik die bewerkstelliging van verhoudings tussen skrywer en lesers/ hoorders, met die klem op die 'rhetorical identification with his audience' (Johnson 1996:247). Vanuit 'n pragmatiese oogpunt demp die inklusiewe woordgebruik die kruheid van die lys deur vir Paulus as deel van die binnekring uit te beeld en nie as 'n regter wat vanuit 'n hoogheilige podium oordeel fel nie.

Die inklusiewe voornaamwoord funksioneer verder om die positiewe beeld van Paulus uit te brei deur hom as nederig uit te beeld. Volgens Hendriksen (1957) dra dit by tot die etos:

it causes the reader (Titus) and the hearers (the Cretan believers when the letter is read to them) to feel that the writer is standing on common ground with them and understands them.

(Hendriksen 1957:387)

Hierdie interpretasie verskaf die nodige onderbou vir die retoriese aard van die diskoers tot dusver. Die argument kan saamgevat word as $n$ argument gegrond op identifisering met die gehoor en dit verhoog die oortuigingskrag van die apostel se argument, naamlik die uitleef van goeie leer, soos in 3:1-2 vervat.

Die woordgebruik van die vers is retories baie insiggewend. Ten opsigte van die retoriese strukturering van die vers is die insette van Collins (2002:358) en Quinn (1990:201) waardevol. Die eerste twee gruwels, naamlik anotht o" en apeigh", bevat albei alfa-priwitiewe. Die byvoeglike naamwoord ap eigh " is 'n geval van paronomasia en word hier vir beklemtoning gebruik. Vroeër (1:16) is dit gebruik om die dwaalleraars te beskryf. In 3:1 verskyn die werkwoordsvorm peigarcei h̀, waarvan a peigh $v$ die teenoorgestelde is. Die effek van die gebruik van a p eigh 4 word in skerp reliëf gebring wanneer die globale verspreiding daarvan in die Titus-brief visueel uitgebeeld word. Dit verskyn as volg:

- ámєєӨ́s (1:16) - negatief, dwaalleraars in die teenwoordige tyd

- $\pi \in € \theta a \rho X \in \hat{i} v$ (3:1) - positief, gelowiges in die teenwoordige tyd

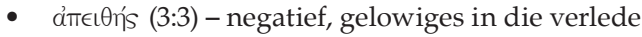

Die oorredingskrag van hierdie tegnieke, herhaling en paronomasia van $\alpha \pi \epsilon \epsilon \theta$ 's is haas onweerstaanbaar. Pragmaties

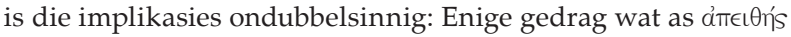


beskryf kan word, is 'n stap agteruit; ' $\mathrm{n}$ stap terug na die verlede; 'n stap in gemeenskap met die dwaalleraars of ' $n$ tree buite gemeenskap met dié wat gehoorsaam is.

Die kombinasie van die paronomasia en die dubbele negatiewe in die twee alfa-priwitiewe bring die afskuwelike aard van ongehoorsaamheid skerp in fokus. Verder word dit met die vilifikasie in 1:10-16 verbind, spesifiek waar' $n$ belydenis van die kennis van God weens onetiese gedrag op'n miskenning van God neerkom (1:16). In 3:3 is die vergrype dus 'n grafiese uitbeelding van die soort gedrag wat getuig van die afwesigheid van 'n verhouding met God. Wat die apostel hierdeur kommunikeer, kan soos volg geparafraseer word: 'Ons was ook soos "hulle"' Hierdie lys konstateer wat vroeër (vgl. bl. 10) as selfvilifikasie gedefinieer is. Die doel van die herinnering van die Kretensers aan hul verlede, spesifiek die skandelikheid daarvan, is om hulle daaroor skaam te laat voel. Die positiewe teenoorgestelde effek is om die onoortreflikheid (of: aantreklikheid) van gesonde leer te beklemtoon en sodoende die oorkoepelende retoriese eindpunt, naamlik gehoorsaamheid aan gesonde leer, by hulle in te skerp.

Die res van die woordeskat dui op 'n merkwaardige samehorigheid en word deur middel van verskeie tegnieke bewerkstellig. Die gevolg is 'n vers waarvan die inhoud dig verweef en gekonsentreerd voorkom - 'n lys van donker gruwels. Quinn (1990:201) demonstreer hoe die gebruik van rymende slotlettergrepe (assonansie) in ol verskeie items op die lys verbind. Hy verbind die woord añolvt oi met die derde woord, pl a nwmenoi, sowel as met die sesde, st ught oi.vDie lys weerspieël 'n kombinasie van asindetiese en sindetiese paring. Met verwysing na eersgenoemde is die afwesigheid van die voegwoord kaivopsigtelik. Met verwysing na laasgenoemde

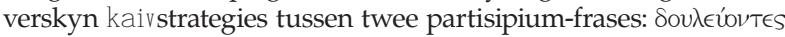

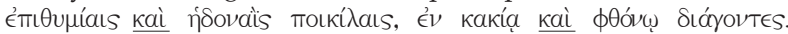
Quinn (1990:201) is waarskynlik korrek wanneer hy die eersgenoemde frase as die 'sentrale giasmus' van die afdeling beskryf. Hy illustreer hoe die giasmus deur die geassoneerde klanke omring word:

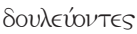

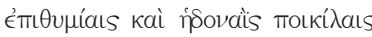

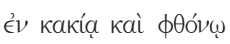

$$
\begin{aligned}
& \text { Sıó́gOVTES }
\end{aligned}
$$

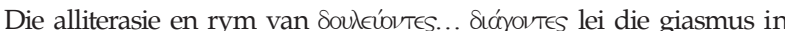
en sluit dit af (Quinn 1990:202). Hierdie giasmus funksioneer

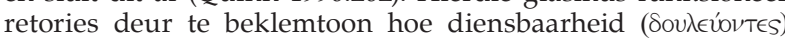

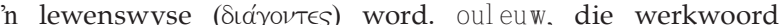
is 'n verdere voorbeeld van paronomasia. ouleúovTES word voorafgegaan deur die selfstandige naamwoord sovìos in sowel die meervouds- as die enkelvoudsvorm in onderskeidelik 2:9 en 1:1. Die gebruik daarvan in 3:3 is 'n voortbouing op die vorige twee gebruike, in dié opsig dat dit hier in 3:3 metafories gebruik word. Albei vorige verwysings kommunikeer die tema van slawerny of dienstigheid positief. In die huidige konteks is dit duidelik negatief en word dit deur paronomasia en metaforiese inkleding onder die loep geplaas. Pragmaties dus, is die implikasie soos volg: Vryheid van 'n aardse of hemelse

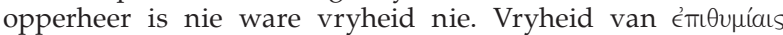

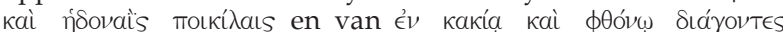
verteenwoordig ware vryheid. Anders gestel: Die werklike slawe is nie diegene wat aardse eienaars dien nie, maar wel diegene wat sonde dien. Dit is interessant hoe die apostel deur die gebruik van die meervoudsvorm van die voornaamwoord na homself verwys as een wat tans 'n dienaar (of: slaaf) van God is (1:1) maar voorheen (тоте́) ook aan sonde verslaaf was (3:3).

Titus 3:3 word in die algemeen soos volg deur navorsers geïnterpreteer: Onthou, ons was nie beter as ander mense nie; daarom, aldus Hendriksen (1957:388), 'let us not be too hard on the people who are still in that condition, but let us strive by godly conduct to win them for Christ'. Hierdie interpretasie ignoreer ongelukkig die verband van Titus 3:3 met die hooffokus van die breër diskoers, naamlik die uitnemendheid, effektiwiteit en noodsaaklikheid van gesonde leer, en vervolgens die dringendheid om daarvolgens te leef.
Die effektiwiteit van die evangelie word beïnvloed deur die mate waarin gelowiges die gesonde leer in die totaliteit van hul lewens onderhou.

Uit Titus 3:3 blyk dit dat die Kretensers nog nie die punt bereik het wat wys dat hulle die noodsaaklikheid van die gesonde leer waardeer nie. Inteendeel, dit blyk dat daar rede is om te glo hulle het hulself aan die invloed van onwettige leraars en hul dwaalleer blootgestel. Gevolglik het hulle skuldig geword aan gedrag wat die integriteit van God se woord (of: die gesonde leer) in gedrang bring. Die twee lyste, naamlik die positiewe lys in 3:1-2 en die negatiewe lys in 3:3, bied die Kretensers die geleentheid om hulle voor- en ná-verlossingsgedragspatrone te evalueer. Hier is twee gedragskategorieë wat nie 'n bestaansreg in die lewens van gelowiges kan deel nie; die een sluit noodwendig die ander uit.

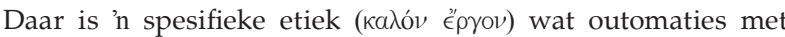
Christen-wees vereenselwig word (vgl. 1:5-9; 2:2-10; 3:1-2 $8 b, 12-14)$. Dit is hierdie etiek wat deur die blootstelling aan $\mathrm{d}$ waalleer in gedrang gebring word.

Die oorkoepelende retoriese oogmerk met Titus 3:3 kan dus soos volg geformuleer word:

Om deur die gebruik van selfvilifikasie weersin in die lesers/ luisteraars te verwek oor die walglikheid van hul sondige gedragspatrone in die verlede en hulle sodoende tot etiese gedragspatrone in die hede aan te moedig wat getuig van onderskrywing van die gesonde leer en wat dit aantreklik vir die res van die samelewing maak.

Soos in die geval van vilifikasie, is vervreemding en omhelsing die oogmerk: vervreemding van sondige gedrag en die omhelsing van Christen-gedrag wat van die gesonde leer getuig.

\section{SLOTOPMERKINGS}

Gevolgtrekkings oor Titus 3:3 is uiteenlopend. Dit funksioneer óf bloot evangelisties, óf verklarend, óf slegs as 'n skets van menslike sondigheid. Inderwaarheid is dít wat in 3:3 gelys word op die Kretensers, Paulus, Titus en die res van die menslike samelewing van toepassing.

Die vorm van vilifikasie wat in hierdie Skrifgedeelte geëien is, is selfvilifikasie. Hierdie retoriese tegniek bied 'n baie bevredigende verduideliking vir die funksie van die lys van vergrype in Titus 3:3. Waar vilifikasie op opponente van toepassing is, is selfvilifikasie op die spreker/skrywer en hoorders/lesers van toepassing. Waar vilifikasie die oogmerk het om die hoorders/lesers te oorreed om hulle van die opponente te vervreem, is dit die oogmerk met selfvilifikasie, ten minste in Titus 3:3, om te oortuig om van negatiewe gedragspatrone weg te breek en positiewe gedragspatrone te toon. In die lig hiervan is die hoof- retoriese doelstelling van 3:3 om deur die gebruik van selfvilifikasie weersin in die lesers/hoorders te verwek oor die walglikheid van hulle sondige gedragspatrone in die verlede en hulle sodoende tot etiese gedragspatrone in die hede aan te moedig. Hierdie gedragspatrone moet getuig van onderskrywing van die gesonde leer, en dit moet die gesonde leer aantreklik vir die res van die samelewing maak.

Die toepaslikheid van selfvilifikasie op soortgelyke Skrifgedeeltes, naamlik waar daar 'n vergelyking getref word tussen die voor- en ná-verlossingsleefstyl, is 'n moontlikheid wat verdere ondersoek vereis. Sodanige Skrifgedeeltes kan 1 Korintiërs 6:9-11, Galasiërs 4:8-10, Efesiërs 2:1-10, en so meer insluit.

'n Ander uitstaande kenmerk in Titus 3:3 is die gebruik van die argument gegrond op identifisering met die hoorders/lesers. Dit versag die skerpheid van 3:3 en verhoog die oorredingskrag van die gedeelte. 
Die lesse uit 3:3 vir vandag is waardevol. Kerke in Suid-Afrika kan nie uit die wêreld onttrek of evangelisasie van die samelewing versuim omdat ons die wêreld as onwaardig of onverdienstelik beoordeel as gevolg van morele vergrype nie. Sou ons dit doen, is die tonikum van Titus 3:3 dat ons eerlik in die spieël van ons geheue na ons voor-Christelike lewens kyk. Dáár word ons gedwing om onsself in al ons naakte onwaardigheid te aanskou en oorweldig te word deur God se genade teenoor onwaardiges soos ons - soos in die daaropvolgende verse ná 3:3 verduidelik word. Wanneer ons dan só die evangelie (of: gesonde leer) uitleef, kan ons deur ons leefstyl en gesindheid diegene wat ons as onwaardig oordeel bring na Hom wat genade aan onwaardiges betoon, met dien verstaande dat ons

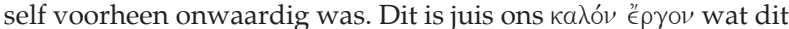
moet bewerkstellig!

Evangelisasie, in watter vorm ook al, moet gemotiveer word vanuit ' $n$ dankbaarheidsperspektief eerder as uit ' $n$ hovaardige, 'ons is beter as julle'-soort ingesteldheid. Net soos in Kreta van ouds is daar 'n menigte mede-onwaardige Suid-Afrikaners wat moet leer dat die verlossing van onwaardiges uit die greep van sonde - in die woorde van die digter Totius - genade, alles net genade is. Laat ons inklim en werk!

\section{LITERATUURVERWYSINGS}

Bailey, M.L., 1994, 'A theology of Paul's Pastoral Epistles', in R.B. Zuck \& D.L. Bock (eds.), A biblical theology of the New Testament, pp. 333-367, Moody Press, Chicago.

Bernard, J.H., 1980, The Pastoral Epistles: Timothy and Titus, Baker Publishing Group, Michigan.

Botha, P.J., 1993, 'The verbal art of the Pauline letters: Rhetoric, performance and presence', in S.E. Porter \& T.H. Olbricht (eds.), Rhetoric and the New Testament: Essays from the 1992 Heidelberg Conference, JSNT Sup, 90, pp. 409-428, JSOT Press, Sheffield

Calvin, J., 1856, Commentaries on the epistles to Timothy, Titus and Philemon, trans. W. Pringle, T. Constable, London.

Chrysostom, D., 1949, 'Dio Chrysostom', trans. J.W. Cohoon, The Loeb Classical Library, vol. 5, 2nd edn., Harvard University Press, Cambridge.

Classen, C.J., 2002, Rhetorical criticism of the New Testament, Brill Academic Publishers, Leiden.

Collins, R.F., 2000 'The theology of the epistle to Titus', Ephemerides Theologicae Lovanienses Tomus LXXVI, 56-72.
Collins, R.F., 2002, 1 \& 2 Timothy and Titus: A commentary, Westminster John Knox Press, Louisville.

Dibelius, M. \& Conzelmann, H., 1972, The Pastoral Epistles: A commentary on the Pastoral Epistles, Fortress Press, Philadelphia.

Du Toit, A.B., 1989, 'Persuasion in Romans 1:1-17', Biblische Zeitschrift 33, 192-209.

Du Toit, A.B., 1992, 'Alienation and re-identification as pragmatic strategies in Galatians', Neotestamentica 26, 279295.

Du Toit, A.B., 1994, 'Vilification as a pragmatic device in early Christian epistolography', Biblica 75, 403-412.

Fee, D.G., 1988, 1 and 2 Timothy, Titus, Hendrickson, Michigan.

Forbes, C., 1986, 'Comparison, self-praise and irony: Paul's boasting and the conventions of Hellenistic rhetoric', New Testament Studies 32, 1-30.

Hendriksen, W., 1957, 1 \& 2 Timothy and Titus, Banner of Truth Trust, London.

Hultgren, A.J., 1984, 1-2 Timothy, Titus, Minnesota, Minneapolis.

Johnson, L.T., 1996, Letters to Paul's delegates: 1 Timothy, 2 Timothy, Titus, Pennsylvania Trinity Press International, Valley Forge.

Knight, G.W. III, 1992, The Pastoral Epistles: A commentary on the Greek text, WB Eerdmans, Grand Rapids.

Marshall, I.H., 2004, A critical and exegetical commentary on the Pastoral Epistles, T\&T Clark International, London.

Miller, J.D., 1997, 'The Pastoral Letters as composite documents', in R. Bauckham (ed.), Society for New Testament Studies: Monograph Series, Cambridge University Press, Cambridge.

Mounce, W.D., 2000, Pastoral Epistles, Thomas Nelson, Nashville.

Quinn, J.D., 1990, The Letter to Titus: A new translation with notes and commentary and an introduction to Titus, 1 Timothy, and the pastoral epistles, Doubleday, New York.

Simpson, E.K., 1954, The Pastoral Epistles: The Greek text with introduction and commentary, Tyndale Press, London.

Tolmie, D.F., 2005, Persuading the Galatians: A text-centred rhetorical analysis of a Pauline letter, Möhr Siebeck, Tübingen.

Towner, P.H., 1994, 1-2 Timothy and Titus, Intervarsity Press, Leicester. 